\title{
Narcissitic Personality Disorder Pada Tokoh Elena Dalam Komik Tomodachi Gokko Karya Momochi Reiko
}

\author{
Komang Triyas Wardhani", Silvia Damayanti, Renny Anggraeny \\ Program Studi Sastra Jepang Fakultas Ilmu Budaya \\ [wardanitriyas@gmail.com] [silvia_damayanti@unud.ac.id] \\ [renny_anggraeny0309@yahoo.co.jp] \\ *Corresponding Author
}

\begin{abstract}
The tittle of this research "Narcissitic Personality Disorder at Character Elena Figure in comic Tomodachi Gokko by Momochi Reiko". The aims of this research are to described NPD Characteristic, the reasons of NPD in character Elena, impact of NPD to Elena and other characters in comic Tomodachi Gokko by Momochi Reiko.The theories that have been used are Wellek and Warren's literature and psychology theory (2016), Sigmund Freud Narcissism theory (1914), Gunderson's Narcissitic Personality Disorder (1994), Lajos Egri's Three Dimensions of Characterrization (1946) and Marcel Danesi's semiotic theory (2011).

Based on the result, Elena is an early adulthood's girl who experiences with Narcissistic Personality Disorder. Characteristic of NPD in Elena based on Gunderson, $d k k$, namely (1) has a grandiose of self-importance and is often envious of others, (2)is preoccupied with fantasies of unlimited success, power, brilliance, beauty, or ideal love. (3) believes that he or she is "special" and unique and can only be understood by, or should associate with, other special or high status people, (4) requires excessive admiration, (5) has a sense of entitlement, (6) is interpersonally exploitative, takes advantage of other to achieve his or her own ends, (7) lacks empathy, and (8) shows arrogant, haughty behaviors or attitudes. The Reason behind Elena's NPD condition was triggered by her mother, as a child she was often got curse word. The impact of NPD to Elena were 1) difficulted for her to distinguish between good and bad deeds and she almost lost her own life, and she move to the new school. The impact Elena's NPD to other people around her were 2) she doing bullying, damaging, and traping for personal gain.
\end{abstract}

Keywords : Psychology literature, Narcissistic Personality Disorders, Psychoanalytic

Abstrak

Penelitian ini berjudul "Narcissistic Personality Disorder Pada Tokoh Elena Dalam Komik Tomodachi Gokko Karya Momochi Reiko". Tujuan penelitian ini adalah untuk mendeskripsikan karakteristik NPD, faktor penyebab, serta dampak NPD pada tokoh Elena dan orang-orang sekitar Elena dalam komik Tomodachi Gokko karya Momochi Reiko. Teori yang digunakan adalah teori psikologi sastra Wellek dan Warren (2016), teori narcissism Sigmund Freud (1914), teori Narcissistic Personality Disorder Gunderson (1994), Teori tiga dimensi penokohan Lajos Egri (1946), dan teori semiotika Marcel Danesi (2011). 
Berdasarkan hasil dari penelitian tokoh Elena adalah seorang siswi yang mengalami NPD pada awal masa dewasa. Karakteristik NPD pada tokoh Elena dijabarkan menggunakan teori Gunderson, dkk, yaitu (1) memiliki pandangan yang dilebih-lebihkan mengenai diri sendiri dan iri pada orang lain, (2) terfokus pada keberhasilan yang tanpa batas, kecerdasan, kecantikan diri atau cinta yang ideal, (3) percaya bahwa diri mereka spesial, unik, dan hanya bisa dimengerti oleh atau kelompoknya, seseorang yang spesial atau memiliki level yang tinggi, (4) membutuhkan kekaguman yang berlebihan, (5) memiliki kebutuhan ekstrem untuk dipuja, (6) perasaan kuat bahwa mereka berhak mendapat segala sesuatu, mengambil keutungan dari orang lain demi keuntungan pribadi, (7) kurang memiliki rasa peduli atau empati, (8) terlihat sangat angkuh dan arogan. Faktor penyebab terbentuknya NPD pada tokoh Elena adalah dipicu oleh ibunya, ketika kanak-kanak Elena sering mendapatkan makian. Dampak yang ditimbulkan NPD pada tokoh Elena adalah 1) Elena sulit membedakan perbuatan baik dan buruk, hampir kehilangan nyawanya sendiri, dan hingga harus pindah sekolah. Dampak NPD yang diderita Elena terhadap orang disekitarnya adalah 2) Dia melakukan perundungan, mencelakai dan menjebak demi kepentingan pribadinya.

Kata Kunci : Psikologi Sastra, Psikoanalisis, Narcissistic Personality Disorder

\section{Pendahuluan}

Setiap individu tentunya memiliki rasa percaya diri baik kepercayaan diri untuk melakukan sesuatu, dan percaya diri terhadap dirinya sendiri.Walker (2016) menyatakan, percaya diri yang normal adalah mereka yang memiliki harga diri sehat. Individu dengan kepercayaan diri normal merasa tidak perlu menjadi pemimpin atau angkuh agar diperhatikan oleh orang lain dan lebih senang membuat hubungan yang baik serta saling mendukung. Individu ini juga memiliki rasa empati, dan memiliki kerendahan hati. Individu dengan kepercayaan diri sehat dapat menerima kegagalan tanpa merasa diri mereka rendah dan merasa kegagalan yang dialami adalah hal yang biasa (dalam situs Walker, 2016), namun hal ini sangat berbanding terbalik dengan seseorang yang memiliki gangguan mental kepercayaan diri atau disebut dengan NPD, mereka dengan gangguan NPD sangat sulit menerima kritikan, kekalahan, atu kegagalan. Karenanya ganguan ini sering kali menyebabkan depresi bagi penderita.

Fenomena NPD kerap kali memengaruhi sastrawan-sastrawan untuk menuangkan fenomena ini ke dalam karya sastra, seperti Shoji Gatoh (2015) dengan karyanya yang berjudul Amagi Brilliant Park. Manga tersebut menceritakan mengenai tokoh bernama Seiya Kanie. Seiya memiliki rasa percaya diri yang tinggi dengan dirinya sendiri, bertingkah seperti pangeran, dan seorang siswa yang perfeksionis, selanjutnya Manga Gekkan Shoujo Nozaki-kun karya Tsubaki Izumi (2011) menceritakan mengenai tokoh 
laki-laki yang bernama Mikoshiba Mikoto. Mikoshiba sangat suka memuji diri sendiri dan sering kali mengatakan bahwa dirinya adalah laki-laki yang tampan. Namun, objek yang akhirnya dipilih sebagai objek penelitian adalah karya Momochi Reiko dalam komiknya yang berjudul Tomodachi Gokko. Dalam komik tersebut terdapat tokoh bernama Elena, Elena merupakan seorang siswi sekolah khusus perempuan di Jepang yang memiliki kepribadian sangat angkuh, senang dipuji, kurang empati, dan sombong. Elena hanya memikirkan mengenai dirinya sendiri dan segala sesuatu yang diinginkan harus dipenuhi, serta menganggap bahwa dirinya pantas menerima perlakuan khusus. Penggambaran tokoh Elena tersebut yang sekaligus menjadi alasan dipilihnya komik Tomodachi Gokko sebagai objek dalam penelitian ini. Selain itu, di dalam komik Tomodachi Gokko juga menggambarkan faktor dan dampak NPD, sehingga komik ini sangat tepat dijadikan data dalam meneliti NPD.

Pada masyarakat umum NPD sendiri seringkali tidak disadari dan dianggap sebelah mata sehingga pada akhirnya dapat berdampak buruk bagi penderita serta orang-orang disekitarnya. Hal tersebutlah yang merupakan salah satu alasan yang memengaruhi para peneliti untuk meneliti NPD, seperti penelitian yang dilakukan oleh Farouqi (2012). Penelitian Farouqi membahas mengenai NPD dalam naskah drama Unubore Deka karya Kudou Kankurou yang mana penelitian yang dilakukan terfokus pada karakteritik NPD dan membahas mengenai faktor penyebab terbentuknya NPD. Mengingat seseorang yang mengalami NPD juga dapat berdampak mengalami depresi, sehingga penelitian ini juga menggunakan penelitian Pasimpangan (2018) yang berjudul "Depresi Tokoh Kousei Arima dalam Manga Shi Gatsu Wa Kimi No Uso Karya Naoshi Arakawa" sebagai acuan. Penelitian Pasimpangan memberikan gambaran seseorang yang mengalami gangguan mental depresi serta faktor penyebab seseorang dapat mengalami depresi.

\section{Rumusan Masalah}

Sesuai dengan latar belakang yang telah dijelaskan, maka adapun rumusan masalah yang dianalisis dalam penelitian ini adalah sebagai berikut.

1. Bagaimanakah karakteristik NPD pada tokoh Elena dalam komik Tomodachi Gokko karya Momochi Reiko?

2. Bagaimanakah faktor penyebab NPD pada tokoh Elena dalam komik Tomodachi Gokko karya Momochi Reiko? 
3. Bagaimanakah Dampak NPD yang diderita oleh Tokoh Elena dalam komik Tomodachi Gokko karya Momochi Reiko ?

\section{Tujuan Penelitian}

Tujuan penelitian ini adalah untuk mengetahui karakteristik NPD, faktor penyebab, serta dampak NPD bagi penderita dan orang-orang disekitar penderita NPD dalam komik Tomodachi Gokko karya Momochi Reiko.

\section{Metode Penelitian}

Penelitian ini merupakan penelitian kualitatif dengan rancangan penelitian sebagai berikut: (1) mengumpulkan data, memahami, dan mengelompokkan data yang dibutuhkan, (2) membaca dan memahami objek penelitian, (3) data-data yang diperlukan dan telah dipahami kemudian dianalisis. Sumber data penelitian berupa komik Tomodachi Gokko karya Momochi Reiko yang berjumlah tiga volume. Setelah sumber data berhasil ditentukan, barulah pengumpulan data dimulai. Data dikumpulkan dengan menggunakan metode kepustakaan dan teknik catat. Data yang telah dikumpulkan kemudian dipahami, lalu dikelompokkan menjadi tiga bagian, yaitu karakteristik pelaku NPD, dan faktor penyebab serta dampak yang ditumbulkan pelaku NPD terhadap tokoh dan dampak yang ditimbulkan tokoh NPD pada orang-orang sekitarnya (Ratna, 2014:39-50). Penelitian ini merupakan penelitian komik berbahasa Jepang dalam bidang Psikologi Sastra, maka dari itu penelitian ini menggunakan Teori Psikologi Sastra dan Teori Semiotika sebagai teori dasar, lalu pada rumusan masalah pertama dianalisis menggunakan teori Narcissistic Personality Disorder oleh Gunderson,dkk (1994), rumusan masalah kedua serta ketiga menggunakan teori Narcissistic Personality Disorder oleh Gunderson,dkk (1994), dan teori Sigmund Freud (1914) dengan metode Deskriptif Analisis. Kemudian, setelah proses analisis selesai, hasil analisis dipaparkan dengan metode informal dan setelah itu disimpulkan.

\section{Hasil dan Pembahasan}

Tokoh Elena merupakan seorang gadis muda yang mengidap NPD pada awal masa dewasa. Adapun karakteristik NPD pada tokoh Elena yang pertama adalah memiliki pandangan yang dilebih-lebihkan mengenai diri sendiri dan iri pada orang lain, sibuk dengan khayalan keberhasilan yang tanpa batas, kecerdasan, kecantikan diri atau cinta 
yang ideal, percaya bahwa mereka spesial dan hanya bisa dimengerti oleh kelompoknya, membutuhkan dan mengharuskan kekaguman yang berlebih, memiliki kebutuhan untuk dipuja, perasaan kuat bahwa mereka berhak mendapat segalanya, serta mengambil keuntungan dari orang lain demi keuntungan pribadi, kurang memiliki rasa empati, dan terlihat sangat angkuh dan arogan. Faktor penyebab munculnya NPD pada tokoh Elena adalah trauma narcissitic masa kecil dan dampak dari NPD pada tokoh Elena adalah sulit membedakan perbuatan yang baik dan buruk, hampir kehilangan nyawanya dan harus pindah sekolah, sedangkan dampak NPD pada orang-orang sekitar Elena adalah merundung, mencelakai, dan menjebak. Berikut merupakan penjabaran mengenai hasil analisis pada karakteristik, faktor penyebab, serta dampak yang ditimbulkan tokoh Elena sebagai penderita NPD pada dirinya sendiri dan pada orang-orang sekitarnya.

\subsection{Karakteristik NPD Pada Tokoh Elena}

Berikut merupakan pemaparan hasil analisis karakteristik tokoh Elena dalam komik Tomodachi Gokko karya Momochi Reiko.

\subsubsection{Memiliki Pandangan yang Dilebih-Lebihkan Mengenai Diri Sendiri dan Iri pada Orang Lain}

Menurut Gunderson, dkk (dalam First, 1994:658-661), seseorang dengan NPD memiliki pandangan yang dilebih-lebihkan mengenai diri mereka sendiri, seperti contohnya mereka dengan NPD kerap kali membesar-besarkan bakat yang mereka miliki meskipun tanpa diminta, mengharapkan untuk diakui seperti orang yang unggul meskipun tanpa prestasi. Dalam komik Tomodachi Gokko karya Momochi Reiko, tokoh Elena digambarkan sebagai tokoh yang suka memamerkan bakatnya di depan teman kelasnya dan sangat iri kepada teman-teman kelas yang jika menjadi pusat perhatian. Karakteristik tokoh Elena tersebut dapat dilihat pada gambar berikut.

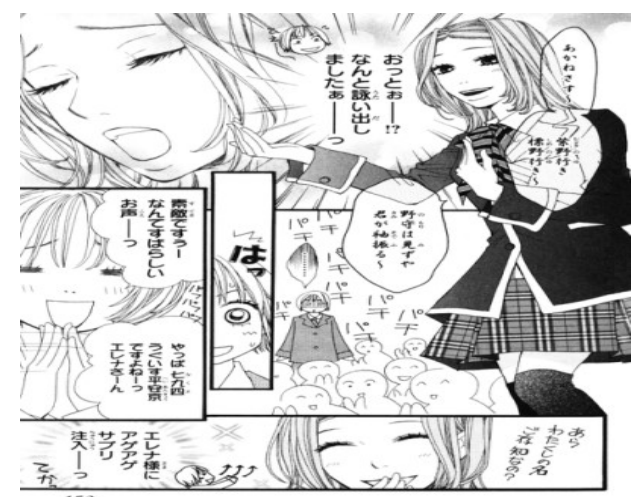




\section{Gambar 1. Tokoh Elena saat memamerkan bakatnya pada siswi baru di depan kelas (Tomodachi Gokko 1,2011:158)}

Gambar (1) merupakan situasi tokoh Elena yang memamerkan bakatnya yaitu membacakan puisi jepang klasik didepan siswi baru bernama Murasaki dan teman kelasnya. Saat itu semua teman kelas Elena sedang memperhatikan siswi baru tersebut memperkenalkan diri, karena sangat lucu dan siswi baru tersebut menceritakan mengenai Tokyo, semua teman kelas Elena sangat antusias mendengarkan dan tertawa melihat tingkah lucu Murasaki, lalu tiba-tiba tanpa diminta Elena maju ke depan kelas dan mengalihkan pandangan teman-temanya agar terfokus pada dirinya. Pada saat itupula Elena memberitahu siswi baru tersebut bahwa dirinya menyukai puisi Jepang klasik, ia lalu membacakan salah satu puisi Jepang Klasik favoritnya dengan suara yang lantang dan menarik perhatian teman-temannya. Sikap Elena tersebut muncul karena Elena sebagai penderita NPD memiliki pandagan yang berlebihan mengenai dirinya sendiri, Elena akan membesar-besarkan bakat yang ia miliki meskipun bakat tersebut hanya bakat biasa, selain itu hal tersebut juga dilakukan tokoh Elena dikarenakan karakteristik Elena sebagai penderita NPD yang memiliki perasaan iri. Perhatian yang seharusnya tertuju padanya beralih ke Murasaki yang hanya seorang siswi baru.

\subsubsection{Terfokus pada Keberhasilan yang Tanpa Batas, Kecerdasan}

\section{Kecantikan Diri atau Cinta yang Ideal}

Menurut Gunderson, dkk, karakteristik NPD yang kedua adalah terfokus pada keberhasilan yang tanpa batas, merasa diri mereka cerdas, terfokus akan kecantikan dan cinta yang ideal (dalam First,1994:658-661).Tokoh Elena pada komik Tomodachi Gokko karya Momochi Reiko memiliki karakteristik yang terfokus pada keberhasilan dalam segala hal yang ia lakukan dan ia inginkan, tokoh Elena akan melakukan apa saja demi mempercantik dirinya, selain itu tokoh Elena juga memanfaatkan teman-teman kelasnya demi mendapatkan cinta dari seorang siswa favorit yang berwajah tampan serta dikagumi oleh semua siswi di sekolah Elena. Karakteristik Elena tersebut dapat dilihat pada gambar dan data berikut. 


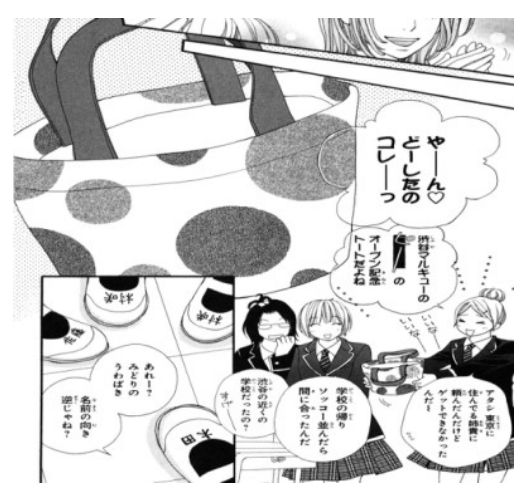

Gambar 2 Teman-teman Elena mengagumi Tote Bag edisi terbatas yang dimiliki Murasaki

(Tomodachi Gokko,1,2011:14)

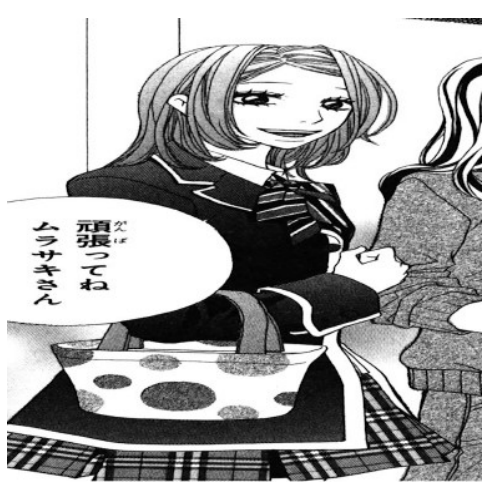

Gambar 3 Elena membawa Tote Bag edisi terbatas milik Murasaki

(Tomodachi Gokko, 1,2011:58)

Gambar (2) merupakan penggambaran saat teman-teman kelas Elena menghampiri Murasaki yang membawa tote bag edisi terbatas dari Shibuya. Seluruh teman Elena mengagumi tote bag tersebut dan menginginkannya. Hal tesebut lalu didengar oleh Elena, ia lalu memerintahkan kelompoknya untuk merampas tote bag tersebut. Pada gambar (3) dapat dilihat Elena tanpa perasaan malu memamerkan tote bag tersebut di depan teman-teman kelasnya dan mengatakan ia sangat cantik menggunakan tote bag tersebut. Selain tega merampas barang miliki orang lain demi mempercantik dirinya, tokoh Elena juga sesekali memerintah teman kelasnya untuk menyisir rambutnya agar selalu terlihat rapi. Hal tersebut dapat dilihat pada gambar berikut.

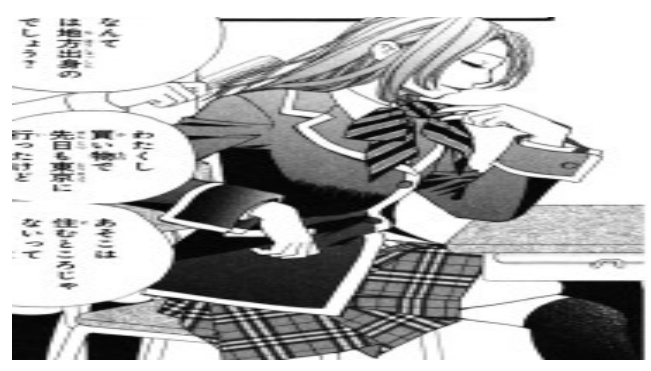

\section{Gambar 4. Tokoh Elena sedang disisir oleh kelompoknya}

(Tomodachi no Gokko

Gambar (4) menunjukkan ketika tokoh Elena sedang disisir rambutnya oleh kelompoknya agar terlihat selalu rapi. Elena akan sesekali memerintahkan kelompoknya untuk merapikan rambutnya ketika jam istirahat, hal ini Elena lakukan agar rambutnya selalu terlihat rapi dan dapat mendukung penampilannya sehingga ia dapat selalu 
dikagumi oleh teman-temannya. Selain terfokus akan kecantikan tokoh Elena juga terfokus dengan kekasih idaman yang ia pikir layak untuk dirinya. Dalam komik Tomodachi Gokko karya Momochi Reiko, tokoh Elena menyukai tokoh bernama Torihada, ia menginginkan Torihada dikarenakan Torihada adalah siswa idaman di sekolah Elena, banyak teman-teman Elena menyukai dan ingin menjadi kekasih Torihada, selain itu Torihada juga merupakan seorang siswa yang berwajah tampan dan pintar dalam bidang olah raga yaitu sepak bola. Setelah mengetahui bahwa Torihada adalah sahabat Murasaki, Elena lalu memerintahkan kelompoknya untuk membawa Torihada kehadapannya. Penggambaran pada tokoh Elena tersebut dapat dilihat dalam data berikut.

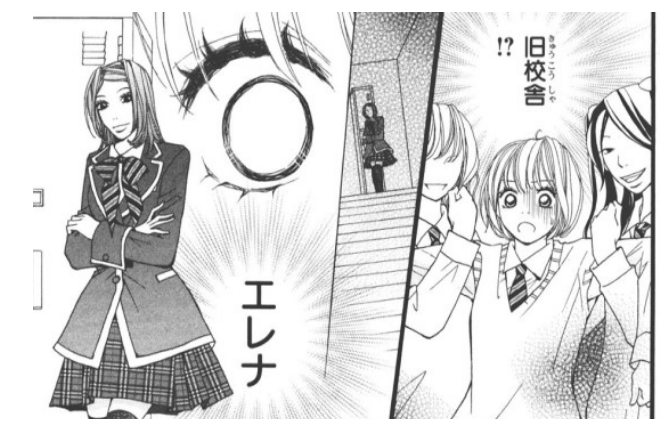

Gambar 5. Kelompok Elena menyeret Murasaki untuk memaksanya mempertemukan Elena dengan Torihada (Tomodachi Gokko, 2, 2011:69

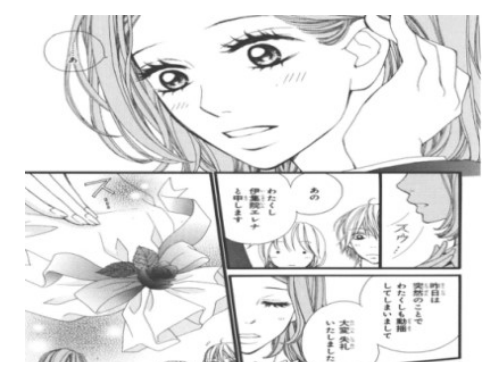

Gambar 6. Murasaki mempertemukan Elena dengan Torihada (Tomodachi Gokko,2, 2011:73

Elena menunggu kelompoknya yang diperıntankan untuk membawa Murasakı secara paksa ke sebuah gedung kosong di sekolah mereka. Elena lalu memerintahkan Murasaki untuk mempertemukannya dengan Torihada, dan menjodohkan mereka. Lalu pada gambar (6) Elena akhirnya bertemu dengan Torihada, Elena lalu bersikap sangat anggun untuk dapat memikat Torihada.

\subsection{Faktor Penyebab Terbentuknya NPD}

Freud menyatakan bahwa pada permulaan hidup manusia energi psikis tidak berkaitan dengan objek luar, melainkan ego (kemauan) merupakan satu-satunya objek dan merupakan tempat atau sumber persemaiaman energi psiki manusia. Pada masa mudanya, anak-anak menyalurkan energi psikis mereka untuk kemauan, dan memiliki sifat kepercayaan diri yang positif. Anak-anak yang pada masa kecilnya sering disalahkan oleh orang tua mereka mengenai hal kecil seperti yang dialami Elena yaitu jika ia tidak merapikan mainannya, ia akan mendapat makian dari ibunya. Perlakuan orang tua yang terlalu berlebihan ketika memarahi anaknya akan mengakibatkan anak 
mengalami trauma narsistik Freud, 1914 (dalam Sandler, 2012:17). Trauma narsistik inilah yang membentuk ego ideal Elena sehingga ia mulai memikirkan mengenai dirinya saja dan mulai beralih ke dirinya yang ia inginkan (Ego Ideal). Berikut Pemaparannya.

\section{Data (3)}

エレナ : 小さい頃、わたくしよく母に叱れたわ.おもち やで 遊んだら、ちやんと元あった場所に片付けなさいて。

$$
\text { (トモダチごつこ 3, 2011:73 ) }
$$

\section{Elena : Chiisaikoro, watakushi yoku haha ni shikararetawa. Omocha de asondara, Chanto moto atta basho ni katazukenasaitte.}

(Tomodachi Gokko 3,2011:74)

Terjemahaan
Elena : Waktu kecil, saya sering dimaki ibu. Setelah bermain,saya harus merapikan dan meletakkan kembali mainan saya pada tempatnya.

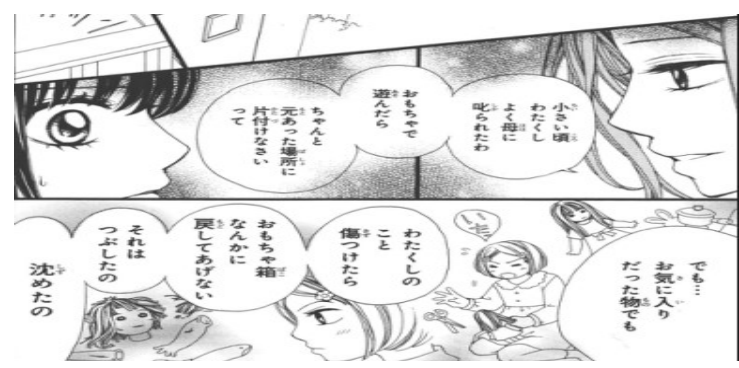

Gambar (7) Elena mengatakan bahwa waktu kecil ia sering dimaki oleh ibunya

(Tomodachi Gokko, 3, 2010:74)

Data (3) dan gambar (7) merupakan pernyataan dan penggambaran Elena kepada AA Chan mengenai masa kecilnya. Pada saat itu Elena merasa kesal terhadap AA Chan yang ingin melakukan balas dendam terhadap dirinya, Elena lalu melontarkan kata-kata mengenai masa kecilnya yang sering dimaki oleh ibunya hanya karena tidak merapikan mainan. Setelah dimaki oleh ibu, Elena bukannya merapikan mainan tersebut, tetapi malah merusaknya dengan cara digunting. Setelah mengatakan pernyataan tersebut Elena lalu melempar handphone milik AA Chan dan mengatakan bahwa AA Chan merupakan mainan yang cukup menyenangkan dan ia harus merusaknya seperti mainan masa kecilnya.

Maka dari pernyataan Elena tersebut tergambarkan secara jelas bahwa semasa kecil ia sering sekali dimaki oleh ibunya, makian ini ia dapatkan hanya karena tidak 
merapikan mainan. Hal tersebutlah yang menyababkan Elena mengalami trauma Narcissistic yang memicu munculnya Ego Ideal. Trauma Narcissitic yang dialami tokoh Elena tersebut merupakan trauma yang muncul bukan berdasarkan beratnya kejadian atau peristiwa yang dialami, namun trauma yang muncul berdasarkan kekuatan mental seseorang tersebut. Maksudnya adalah tidak semua anak-anak yang sering mendapat makian atau diabaikan orang tua mereka akan mengalami trauma, namun hal tersebut tergantung juga kepada keadaan mental seorang anak. Hal-hal yang mungkin dianggap biasa saja bagi seseorang, belum tentu dianggap biasa saja oleh orang lain dan tentu saja dapat memicu traumatis, inilah yang disebut dengan trauma subjektif Howel, 2011 (dalam Hunter, 2018:122). Selain keadaan mental, cara orang tua mengasuh dan memberikan perhatian kepada anaknya juga menjadi alat yang sangat penting pada pertumbuhan psiki anak, seperti yang dikatakan Iswidharmanjaya, 2007 (dalam Aprilia, 2015) menyebutkan bahwa pola asuh orang tua sangat memberikan dampak terhadap pertumbuhan psikis anak-anak. Sikap orang tua dalam berinteraksi dengan anakanaknya dapat meliputi yaitu cara orang tua memberi aturan-aturan, hadiah maupun hukuman,cara orang tua menunjukan otoritas dan juga cara orang tua memberikan perhatian serta tanggapan kepada anaknya. Dalam hal informasi dan cermin tentang diri seseorang, orang tua memegang peranan yang paling istimewa. Jika orang tua secara tulus dan konsisten menunjukkan cinta dan sayang maka akan memberikan pandangan kepada anak bahwa dia pantas dicintai baik oleh orang lain maupun dirinya sendiri, Sebaliknya, jika orang tua tidak memberikan kehangatan, penerimaan dan cinta dalam hubungan dengan anak, maka anak akan tumbuh dengan rasa percaya diri yang kurang.

\subsection{Dampak NPD}

NPD pada Tokoh Elena menyebabkan ia selalu berkeinginan menjadi perempuan yang selalu diperhatikan oleh teman-teman kelasnya, selalu ingin dipuja, dan hanya mementingkan dirinya saja, sehingga saat hal-hal yang ia kehendaki tidak ia dapatkan atau seseorang menyinggung perasaannya, Elena akan marah dan melakukan tindakan balasan yang menyimpang (Gunderson, dkk dalam First,1994:659). Dalam komik Tomodachi Gokko karya Momochi Reiko, Elena sebagai penderita NPD mengalami kesulitan untuk membendakan perbuatan baik dan buruk, sehingga berdampak pada dirinya sendiri dan orang-orang disekitarnya. Dampak NPD pada diri Elena antara lain mempermalukan dirinya demi membalas dendam, hampir kehilangan 
nyawanya, dan pindah sekolah. Lalu dampak NPD Elena pada orang sekitar Elena antara lain merundung, mencelakai, dan menjebak. Berikut pemaparan salah satu dampak NPD tokoh Elena pada dirinya sendiri, dan orang sekitarnya.

\subsubsection{Dampak NPD pada tokoh Elena}

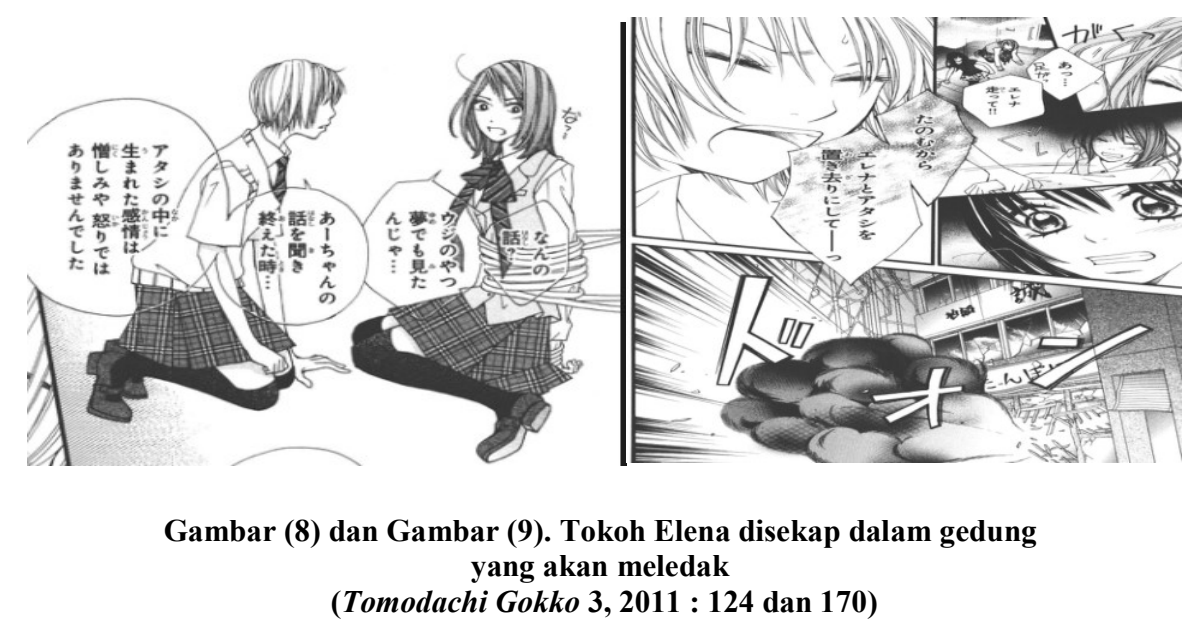

Gambar (8) dan gambar (9) menunjukkan tokoh Elena diikat dengan tali oleh Murasaki di sebuah gedung kosong yang akan meledak. Hal ini dilakukan tokoh Murasaki karena tidak terima Elena telah menjebak sahabat kecilnya yaitu Torihada, mencelakai AA Chan hingga koma, dan mencelakai ibu Torihada. Tokoh Elena melakukan hal tersebut karena ia tidak mendapatkan apa yang ia inginkan dari tokohtokoh tersebut, dan Elena merasa tokoh-tokoh tersebut telah menyakiti hatinya dan berusaha melawan dirinya, karena perbuatannya itu ia membuat tokoh Murasaki marah dan ia hampir saja kehilangan nyawanya sendiri demi kepentingan pribadinya. Elena hampir kehilangan nyawanya di dalam gedung kosong tempat Murasaki meyekapnya.

\subsubsection{Dampak NPD pada orang-orang sekitar Elena}

NPD pada Elena tidak hanya berdampak pada dirinya sendiri namun juga berdampak pada orang-orang disekitarnya. Elena sebagai tokoh NPD, ketika tidak mendapatkan perhatian dari teman-temannya, diabaikan, dikecewakan dan melihat orang lain lebih unggul dari dirinya, Elena akan mengeluarkan reaksi yang menyimpang pada orang-orang disekitarnya. Pada komik Tomodachi Gokko karya Momochi Reiko, tokoh Elena sebagai penderita NPD melakukan perundungan, mencelakai, dan menjebak orang-orang sekitarnya. Dampak salah satu NPD tokoh Elena pada orangorang disekitarnya dapat dilihat pada data berikut. 


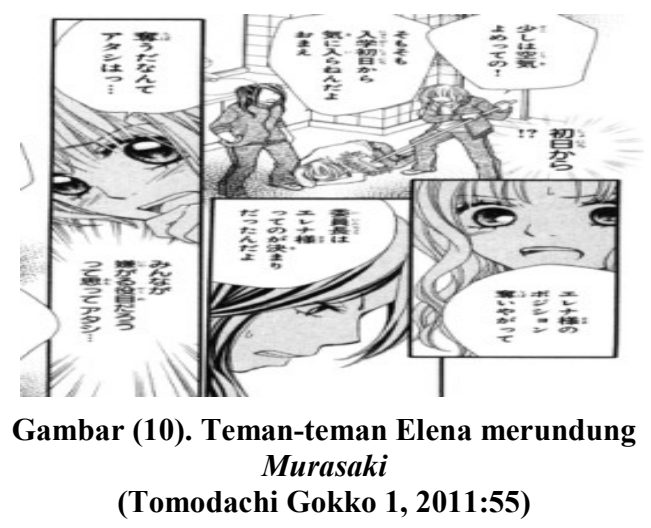

Gambar (10) menunjukkan teman-teman Elena yang merundung Murasaki. Teman-teman Elena merundung Murasaki karena perintah dari Elena. Elena merasa kesal bahwa Murasaki telah dipilih oleh wali murid untuk menjadi ketua kelas dan telah merebut posisi Elena. Teman-teman Elena membawa Murasaki kedalam toilet lalu memukul Murasaki dengan alat mengepel lantai sambil memaki Murasaki.

\section{Simpulan}

Gangguan karakteristik NPD dalam komik Tomodachi Gokko karya Momochi Reiko diidap oleh tokoh bernama Elena yang merupakan seorang siswi perempuan di Sekolah Menengah Atas. Karakteristik NPD pada tokoh Elena dianalisis dengan menggunakan teori Gunderson, dkk (dalam First 1994:658-661). Adapun karakteristik NPD pada tokoh Elena adalah memiliki pandangan yang dilebih-lebihkan mengenai diri sendiri dan iri pada orang lain, sibuk dengan khayalan keberhasilan yang tanpa batas, kecerdasan, kecantikan diri atau cinta yang ideal, percaya bahwa mereka spesial dan hanya bisa dimengerti oleh kelompoknya, membutuhkan dan mengharuskan kekaguman yang berlebih, memiliki kebutuhan untuk dipuja, perasaan kuat bahwa mereka berhak mendapat segalanya, serta mengambil keuntungan dari orang lain demi keuntungan pribadi, kurang memiliki rasa empati, dan terlihat sangat angkuh dan arogan.

Kedua, Faktor penyebab NPD dianalisis dengan teori Freud tahun 1914 (dalam Sandler, 2012:32) dan dampak NPD dianalisis dengan teori Gunderson, dkk (dalam First, 194:659). Faktor penyebab munculnya NPD pada tokoh Elena adalah trauma Narcissitic masa kecilnya yang diceritakan bahwa tokoh Elena sering mendapat makian dari ibunya sendiri. Trauma yang dialami Elena merupakan trauma yang muncul akibat tidak kuatnya mental Elena pada saat kanak-kanak menerima makian dari ibunya yang lalu membentuk Ego Ideal dan membentuk karakteristik NPD seperti pada penjelasan 
sebelumnya. Terakhir adalah dampak NPD pada tokoh Elena dan dampak NPD tokoh Elena pada orang-orang sekitarnya. Dampak pertama NPD pada tokoh Elena adalah tokoh Elena sulit membedakan perbuatan yang baik dan benar bahkan ia rela mempermalukan dirinya demi membalaskan dendam pada seseorang yang mengecewakannya, serta tokoh Elena hampir kehilangan nyawanya sendiri karena NPD yang ia derita. Lalu yang terakhir adalah dampak NPD pada tokoh Elena terhadap orang-orang sekitarnya. Tokoh Elena akan melakukan apa saja bahkn melakukan serangan balasan yang menyimpang terhadap orang yang tidak mau menurut kemauannya atau menentang dirinya. Pertama tokoh Elena melakukan perundungan terhadap tokoh Murasaki, dan tokoh Ujihara, tokoh Elena juga mencelakai ibu torihada, dan menjebak tokoh Torihada hingga ia dikeluarkan dari sekolah.

\section{Daftar Pustaka}

Davison,dkk. 2014. Psikologi Abnormal edisi ke-9 diterjemahkan dari buku aslinya Abnormal Psychology-Ninth oleh Noermalasari Fajar. Jakarta: Rajawali Pers.

Danesi, Marcel. 2010. Pesan, Tanda, dan Makna: Buku Teks Dasar Mengenai Semiotika dan Teori Komunikasi (Diterjemahkan dari Message, Sign, and Meanings: A Basic Textbook in Semantics and Communications Theory oleh Evi Setyarini dan Lusi Lian Priantari). Yogyakarta: Jalasutra.

Farouqi Ismail.2012. "Narsisme Tokoh Utama dalam Naskah Drama Unubore Deka Karya Kundou Kankuro”(skripsi). Jatinangor: Universitas Padjadjaran Fakultas Ilmu Budaya.

First, B Michael. 1994. Diagnostic and Stastistical Manual of Mental Disorder- Fourth Edition. Amerika: American Psychiatry Publishing.

Hunter, Noel. 2018. Trauma and Madness in Mental Health Servies. New York: Springer International Publishing AG

Momochi Reiko.2011. Tomodachi Gokko 1. Japan: Kodansha Ltd Tokyo.

Momochi Reiko.2011. Tomodachi Gokko 2. Japan:Kondansha Ltd Tokyo.

Momochi Reiko.2012. Tomodachi Gokko 3. Japan:Kondansha Ltd Tokyo.

Pasimpanagn, 2018. "Depresi Tokoh Kousei Arima Dalam Manga Shi Gatsu Wa Kimi No Uso Karya Naoshi Arakawa” (Skripsi) Denpasar : Universitas Udayana

Ratna, I Nyoman Kutha. 2009.Teori, Metode, danTeknik Penelitian Sastra. Yogyakarta: Pustaka Pelajar. 
Sandler, dkk. 2012. Freud's On Narcissism AnIntroduction. London: Karnac Books Ltd.

Walker, Marie Hartwell. 2016. Narcissitic Personaliy Disorder vs Normal Narcissim. https://psychcentral.com/lib/narcissistic-personality-disorder-vs-normalnarcissism/(diunduh 20 Mei 2017)

Wellek, Rene. Warren, Austin. 2016. Teori Kesusastraan diterjemahkan oleh Melani Budianta. Jakarta: PT Gramedia Pustaka Utama. 